\title{
Application of Quality Analysis Method to Identify the Best Interaction Style of Parent Companies and Their Subsidiaries
}

\author{
Ebrahim Raesi Sarkandiz ${ }^{1}$, Alireza Irajpour ${ }^{2}$ \\ ${ }^{1} \mathrm{Ph}$.D. student of Industrial Management, Specialty of Production and Operation, Islamic \\ Azad University of Qazvin. \\ ${ }^{2}$ Assistant Professor of Industrial Management, Specialty of Production and Operation, \\ Islamic Azad University of Qazvin. airajpour@yahoo.com
}

\begin{tabular}{ll}
\hline ARTICLE INFO & ABSTRACT \\
$\begin{array}{l}\text { Keywords: } \\
\text { Parent } \\
\text { organization, } \\
\text { project, value } \\
\text { chain, value }\end{array}$ & $\begin{array}{l}\text { Identifying the effective factors in improving project performance } \\
\text { is one of the most important issues that researchers in the field of } \\
\text { preation, } \\
\text { qualitative content } \\
\text { analysis }\end{array}$ \\
$\begin{array}{l}\text { project-oriented organizations, which have a more complex value } \\
\text { chain. Accordingly, with the goal of helping and better influencing } \\
\text { the parent organizations on their own projects and creating value for } \\
\text { them, design of the optimal style of interaction of the project- } \\
\text { oriented parent organizations with subsets using the results of data } \\
\text { qualitative content analysis was done by the authors of this paper in } \\
\text { order to guide the researchers of this field toward the mentioned } \\
\text { direction and conducting the field and case studies. In order to } \\
\text { achieve the mentioned optimal style, first of all, the capabilities of } \\
\text { the project-oriented parent organizations must be identified with a } \\
\text { suitable approach and categorized in a coherent system that forms } \\
\text { the organizational capability dimensions and taken action to } \\
\text { formulate the optimized style based on the findings and } \\
\text { achievements. While, this paper is the first scientific document of } \\
\text { the Ph.D. thesis of the research team of the authors of this article, } \\
\text { addresses and invites other researchers and enthusiasts of this field } \\
\text { to address the issue in various statistical societies. }\end{array}$ \\
\hline
\end{tabular}

\section{Introduction}

The history of project management in the world is generally related to the management of large projects, such as the construction of Egyptian pyramids, wall of China, or construction of Persepolis by order of Darius. All of these projects are among the great and complex projects of human history that have been made with high standard of quality and use of great human power. When a project manager goes to the Achaemenid's mysterious city and looks the ancient outstanding artistic designs at each corner of it, he undoubtedly gets astonished at how such a huge project has been constructed about two thousand five hundred years ago, with such unique quality that in spite of continuous devastation and burning by Alexander and conquerors after him, it is still mentioned as an amazing symbol of the Iranian project. Also, according to order of Cyrus, the Pasargad's engineers and builders were obliged to carve their work description and the next day's work plan on the tablets known as Carnamac, today, 
except by relying on guesses, definite comment on how to manage the great projects of the ancient era cannot be presented. Because, unfortunately, there has been no evidence of how to use the methods and techniques of project management in these projects, so far.

But, the history of project management in the new world dates back to the early 1900s, when Henry Gantt, with the development of his own innovated bar chart, initiated a fast movement during 1950s and 1960s in US military and airborne projects followed by England. Although the well-known name of Henry Gantt as the father of project's control and plan techniques is recorded in the history, the 1950s and 1960s are known as the early years of developing project management in contemporary world (Haj Shirmohammadi, 2004). Now and over a century after the emergence of new project management, projects' beneficiaries are not satisfied with the way projects are implemented, and there are plenty of distance to achieve the right conditions.

In recent years, in studies conducted by O'Connor and Reinsborough (1992), CookeDavies (2002), Zeynep et al., 2008, Yang et al. (Yang et al., 2015) and also, Douglas et al. (2017) and Chen et al (2018), this issue is obvious. Also, according to Kerzner (2009) and Verzuh, (2015), the success of project is determined by the actions and policies of project manager and their team, the parent organization, and the customer organization. Due to the direct and indirect effects of parent organization on its projects and project management performance, it can be allocated a distinct place. According to researches conducted by Jensen et al. (2006) and Jun et al., (2011), this organization can apply both a negative and deterrent effect and a positive and boosting effect on project outcomes. In most cases, the factors related to the parent organization are considered as key factors in success of the project (Balassa and Tukel, 1996). The results of research conducted by Lind kvist (2004), Terry and Geguire., (2007) on the success of projects and effect of parent organization on it show that this issue is of double importance in projectoriented organizations that have a complicated value chain.

These organizations need to have a number of capabilities that help them accomplish their tasks in order to have the greatest impact on their projects based on the nature of their business. These capabilities consist of knowledge, skills, experience and other human and physical resources that help the organization accomplish its mission (Chandler, 2007).

Possessing the proper capabilities for successfully executing projects as one of the components of the project's governance system in the context and implementation of the project has also been highlighted by Turner (2016). However, in spite of the importance of the parent organization's impacts and its potentials to better apply these effects, there has not been a collaborative research that identifies the capabilities of the project-oriented parent organization to influence its projects. Identifying these capabilities will help project-oriented organizations focus on developing and acquiring them and gain competitive advantage considering the competitive and environmental conditions. In this study, identifying the capabilities of a project-oriented parent organization is regarded in order to design an optimal style of interaction of projectoriented parent organizations with subsets. Therefore, the literature of the subject is first examined and then the proposed method for implementation of this research is described below. 


\section{Research background}

The background of the research subject with considered approach comes back to the 1990, when Chandler (1990) divided the organization's capabilities into two categories of strategic capabilities and operational capabilities by providing a conceptual framework. Strategic capabilities relate to the company's capabilities to move quickly towards growing markets rather than competitors. Operational capabilities are also needed to improve research and development, product design, and manufacturing and distribution of the company (Barney, 1991). These types of capabilities are developed and applied by middle managers (Eisenhardt and Martin, 2000).

Project-oriented organizations with complex value chain have been emerged in recent years as a new structure for integrating a diverse range of resources and expertise. In documentations of organizational capabilities, key words, such as resources, capabilities, competencies and routines are expressed in the organization (Davies and Brady, 2000). Organizations that do many of their activities as projects or in their structure and processes emphasize on project approaches than other ones are called project-oriented (Lind kvist, 2004). In these types of organizations, production functions are managed in the form of a project organization that has a defenite (temporary) time frame (DeFillippi and Arthur, 1998) and the project is the most important factor for providing services, creativity and competition (Hobday, 2000).

Studies of Hamel and Prahalad, (1994), and then the work of Teece and Pisano (1997) show that successful organizations develop determinant and dynamic competencies into the external environment. According to Chandler (2007), a company is a set of organizational capabilities, including physical resources, equipment and facilities for producing goods or providing services by the organization, and these capabilities are essential for the organization's ability to grow in new or current markets. Studies of Barney (1991) and Hamel and Prahalad (1994 show that subject of organizational capabilities are largely originated from issues related to resource-based viewpoints. Accordingly, the company is a collection of resources that are non-homogeneously distributed in its whole. Other researchers also recognize the capabilities of the organization as knowledge, special skills, organizational roles, and its experiences (Richardson, 2012). Others have identified four dimensions for the organization's capabilities, such as: knowledge and skills, technical systems, management systems, values and norms (Rabbiosi and Santangelo, 2013).

According to the results obtained from conducted researches, these features can both enhance the organization's synergy, and create a deterrent role to the organization by creating a number of barriers to creativity and creativity (Vadastreanu and Farcas, 2016). In this regard, we point out some of the domestic research that has been done in recent years about parent organizations. Sobhie et al. (2011) examined the management of projects' portfolio in project-oriented organization. In the same year, Aali et al. (2011) reviewed the new approach in strategy of Holding companies titled segregation against ownership (High et al., 2011). The study of the relationship between environmental uncertainty and organizational structure of the commercial parent company of the Islamic Republic of Iran was carried out in this year (Mazloomi, 2011). Hanafizadeh et al. (2011) reviewed the electronic readiness assessment in the subsidiary companies of parent company. Asgari et al. (2011) conducted another research that determined the the factors influencing the completion of capital asset ownership plans in the executive 
parent company of the buildings and public facilities. Nazari et al. (2012) provided a template for project portfolio management in research project-oriented organizations. Stack et al. (2012) conducted a study titled "Providing a framework for selecting the appropriate inter-organizational development method".

Azar et al. (2013) examined the adaptability of organizational performance measurement models in project-oriented organizations. Also, in the same year, Sobhie et al. (2013) reviewed the strategies to improve projects' portfolio management in contracting project-oriented organizations (Sobhie et al., 2013). Mohaghar et al, (2012) conducted a research on identifying the capabilities of the project-oriented parent organization. Determining the legal nature of specialized parent companies and their relationship with subsidiary companies and government was another study that was conducted in the same year (Fasihizadeh et al., 2013). In the same year, Abdeh Tabrizi et al. reviewed the requirements of organizing in form of holding for financial systems of corporations in Iran (Abde Tabrizi et al., 2013). Gholizadeh et al. (2013) also examined the effectiveness of internal auditing on improving internal controls and performance of specialized parent and affiliated companies of the Mostazafan Foundation of the Islamic Revolution of Iran (Gholizadeh et al., 2013). The latest related research conducted by Mohammadi and Abdi (2013) that explained about the strategic functions of public relations in holding companies (Mohammadi et al., 2013). Mirashkari et al. (2014) analyzed the legal of holding company. A study was conducted titled "Valuation of the parent organization's value-generated decisions in subsidiary companies" (Hanafizadeh et al., 2015). The latest research recorded in recent years has also been dedicated to Arbabi et al. (2016) who have explored the value-generated functions of parent organization in oil industry projects. (Arbabi et al., 2016).

Features of the optimal interaction style in project-oriented organizations

From 1950 to 1980 , out of a total of 200 major companies in the UK, about $75 \%$ of them acquired a large part of their sales from a single business. But this approach changed in 1980, and since this year only $35 \%$ of these companies have been focusing on a single business, so far and this figure is gradually declining. It reflects this notion that large corporations are oriented to a complex multi business value chain. Consequently, it is not exaggerated to say that the developed economies of the world are now significantly dependent on the performance of multi business companies. One of the key and strategic issues in management of parent and multi-specialized companies is how these companies interact with their subsets. One of the major challenges of managing parent organizations is that in which areas parent company should support subsets to achieve synergy and in which areas it should not interfere to facilitate doing processes in the organization. Accordingly, first, the actions of parent organizations against the subsets should be examined to determine whether the parent organization's functions are valuable to the subset or not. This research will focus on the characteristics of organizations that are effective in achieving the goals of projects and addresses to the effectiveness and value-generating of the parent organization for its subsets. Turner (2009) is one of the scholars who have studied the subject of the system governing the project. A remarkable point in his research is that in the secondary layer of the Turner model, the field in which the projects are implemented is pointed out and it is stated that the project-oriented organization must ensure the existence of the infrastructure and necessary features to effectively achieve the goals of projects. It 
requires the investigation of two presumptions. The first is related to the infrastructure of portfolio management and Project management, which are defined to link the projects to the strategies of the parent organization. The latter is related to ensuring the existence of necessary capabilities in the organization to run the projects correctly. These capabilities are composed of three major components of project management knowledge, project management methodology, and technical skills. Obviously, people's capabilities are of the main components of organizational capabilities (Chandler, 1990). Davies and Brady (2009) consider a third-party feature as project management capabilities for organizations that are project-oriented and are obliged to produce products in a complex value chain. These organizations are important in the early phases where projects are more influential (Mantel, 2001). Project capabilities are also important during project implementation (Milosevic and Patanakul, 2005). Documenting and implementing a definite approach for organization, along with a true organizational culture-making, is also considered as another feature for project-oriented organization in form of the project management methodology (Brown, 2008). Also, having a dynamic organizational structure that proportional to the needs of the project can adapt itself to the newfound terms of each project (Woodward, 2016) is another feature that is important in project-oriented organizations (Kerzner, 2009).

Qualitative analysis of content and its application in the research

Content analysis is a useful research approach. In this approach, important components or parts of the content of the existing data message are identified and considered, and are sometimes compared with other similar statistics across the entire society. Content analysis in the early years was used for objective, regular, and quantitative description of explicit communication content and was first used in 1950, as many authors have referred to the use of content analysis in many traditional research that often has been quantitative. However, gradually, over time, the use of content analysis included the interpretation of hidden content.

At the moment, two methods of applying content analysis are used. One is a quantitative approach that is often used, such as media research and another one is quality approach, which is often used in educational and research cases.

Table 1 - Comparison of the capabilities of quantitative and qualitative analysis methods

\begin{tabular}{|c|c|c|}
\hline $\begin{array}{c}\text { Qualitative analysis } \\
\text { methods }\end{array}$ & $\begin{array}{c}\text { Quantitative analysis } \\
\text { methods }\end{array}$ & Capability title \\
\hline Relatively low reliance & Relatively high reliance & $\begin{array}{c}\text { Relying on existing literature } \\
\text { and previous evidence }\end{array}$ \\
\hline $\begin{array}{c}\text { More answers to "how" } \\
\text { and "why" }\end{array}$ & $\begin{array}{c}\text { More answers to "what" } \\
\text { and "how much" }\end{array}$ & $\begin{array}{c}\text { The nature of the goals and } \\
\text { research questions }\end{array}$ \\
\hline $\begin{array}{c}\text { Without control or } \\
\text { relatively low control }\end{array}$ & $\begin{array}{c}\text { Relatively high control } \\
\text { Like quantitative } \\
\text { methods }\end{array}$ & $\begin{array}{c}\text { The amount of control over the } \\
\text { actual behavior of phenomena }\end{array}$ \\
\hline $\begin{array}{c}\text { The amount of data } \\
\text { mannot be determined at } \\
\text { beginning of the research } \\
\text { until the theoretical } \\
\text { saturation is achieved }\end{array}$ & $\begin{array}{c}\text { It requires a large and } \\
\text { adequate sample }(30- \\
\text { 500) for a conclusion } \\
\text { about the community }\end{array}$ & Amount of data \\
\hline
\end{tabular}




\section{Suggested method for the research}

Considering the dimensions and coordinates obtained from the previous research, content analysis should be used in this research. Indeed, scholars who use qualitative content analysis believe that in qualitative content analysis, the researcher transcends counting the word alone or extracting objective content, and goes toward understanding meaning of the texts, patterns, and themes that may or may not appear in the outward of a text. This allows the researcher to understand the social reality in a subjective, but scientific sense. With regard to the different stages of quantitative and qualitative content analysis, Krippendorf believes that the distinction between quantitative and qualitative content analysis is a gross error between two types of arbitration about the design of content analysis.

The clarity and objectivity of scientific data, on the one hand, and the appropriateness of the applied procedures in relation to the text on the other, are essential for analysis. (Adel Mehraban and Doosti Irani, 2015). Considering these cases, and also according to the results obtained from researches of Yin (2009) and Creswell (Creswell, 2003), and given the nature of the question used in the research on the capabilities of the project-oriented parent organization that is of kind quiddity and the behavior of the phenomenon studied cannot be controlled (Lincoln, 1985), therefore, we attempt to get deep knowledge and mutual understanding of the mentioned phenomenon with a semistructured interview and an mutual conversation with well-known and proficient individuals (Lincoln, 2005).

Designing and determining the stages of doing research is proposed based on a combination of practices introduced in Richard et al. (2005) and Yin, (2009) and based on the method of using a case study. Richard et al. (2005) published a book entitled "Research Methods in Organizations", which consists of five chapters and consists of 23 articles, which, in a systematic approach, outlines the framework for conducting such research in the mind of the researcher.

In 2009, Yin published a book entitled "Application of Case Study Researches". The book also included five chapters that the first chapter describes the literature of the subject, the second and third chapters describe the method of work in case study, Chapter 4 explains the mutual integration in the case study, and the fifth chapter presents the methods of assessing the work done in regard to achieving goals. The main question raised in semi-structured interviews with selected experts (directors and experts from the parent organization and project-oriented organizations from the statistical community of this research) is that: "In addition to the pathology of the present situation, what actions are taken by parent organization in regard to increase valuegenerating in the project management? "

Therefore, the main tool for collecting data is interview, which are conducted about selected topics at two levels of senior managers and experts of the parent organization and managers and practitioners of the project. Further, organizational documents and outcomes from knowledge management systems in the organization (if available) are discussed. Data analysis will be done in the same direction and with orientation towards answering the research question. In order to assess the validity of the obtained results, structure validity and reliability criteria will be used. In order to obtain structure validity, various information sources, such as interview and reviewing the documents 
and evidence are used and to enhance the reliability, the case study protocol and case study data banks are used (Yin, 2009).

Selection of the items will be carried out using a prioritization method, which is an improbable method. To analyze data from case studies, the methods of coding and qualitative data analysis will be used. According to these method, a series of predefined codes is firstly determined based on the research subject and used in coding of interviews and data as the basis. Some of these codes change during the data analysis and also, new codes will be added to the collection.

In continue, more comprehensive assessments on the extracted code will be done in the first step to organize them in codes being abstractedly at a higher level. Primary encoding, revising and updating existing codes and categorizing them at higher conceptual levels is performed by the repetition logic at the end of each case investigation, in order to eventually do a theoretical saturation and stop the investigations. The diagram of implementation steps of the research methodology is presented in Fig. 1. In order to increase the accuracy and speed of analyses, use of software, such as ATLAS, MAXQDA and NVIVO is recommended. An image of the ATLAS qualitative analysis software environment is presented in Figure 2. 


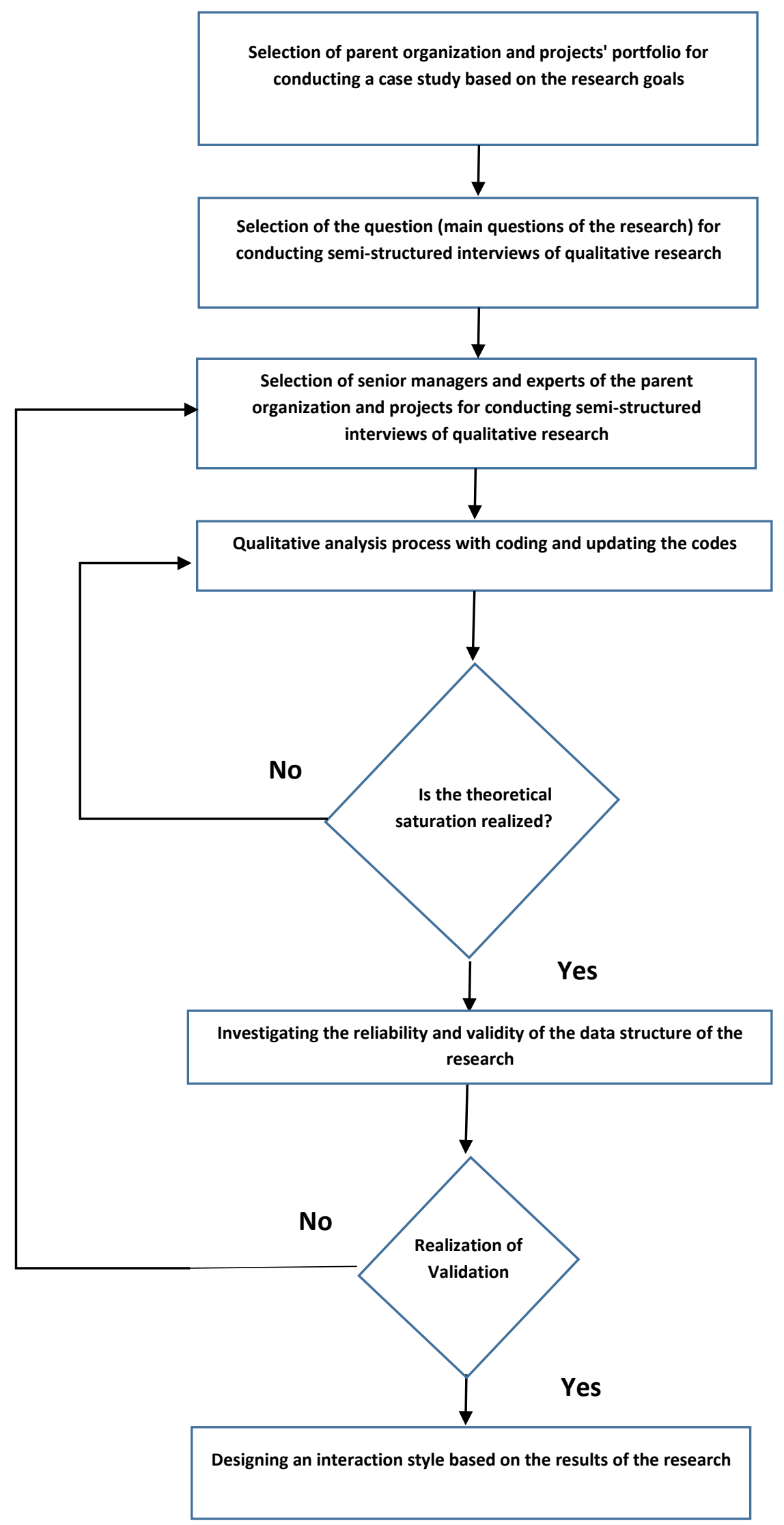

Figure 1. Diagrams of the research methodology steps 


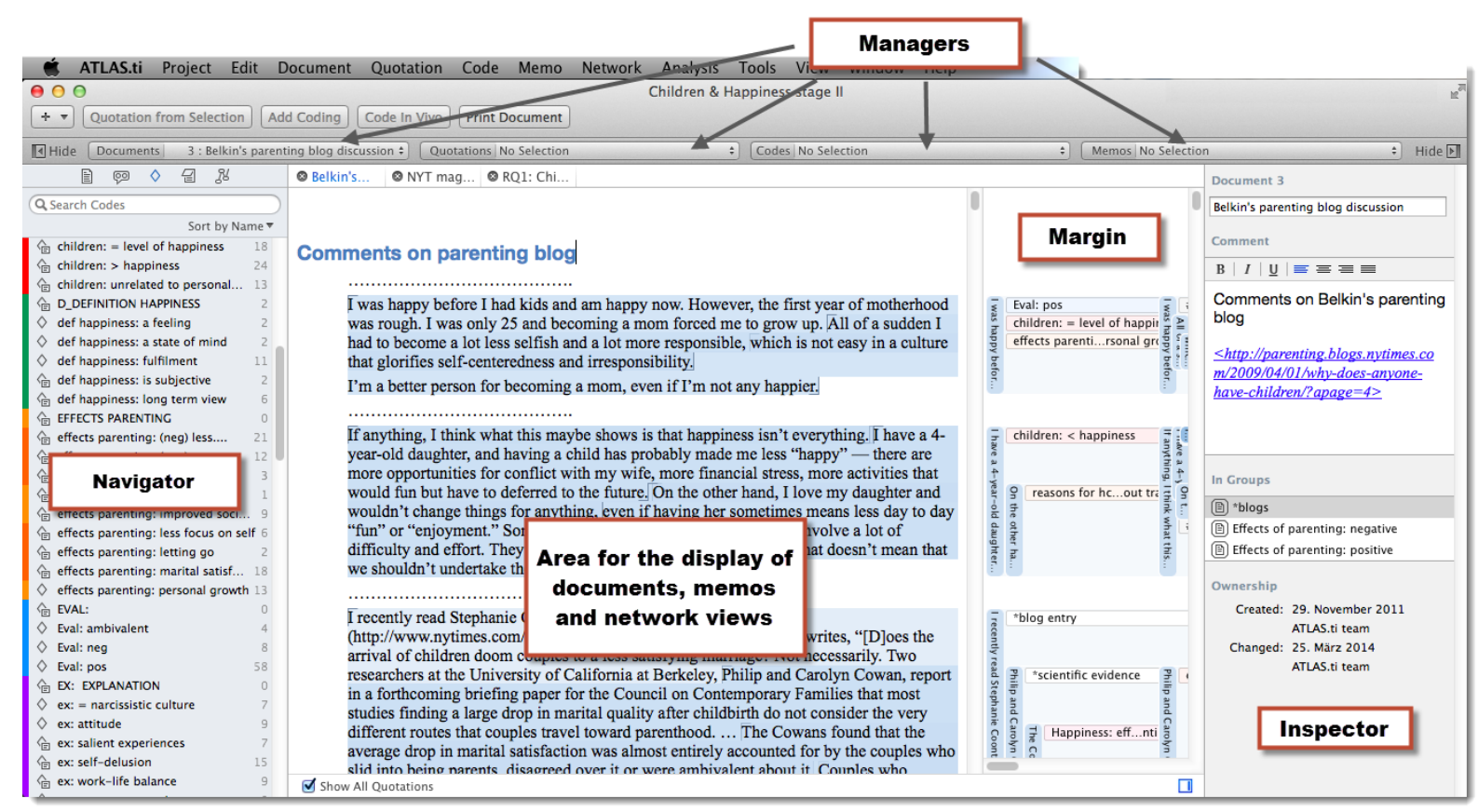

Figure 2. An Image of the Atlas ti qualitative analysis software

\section{Conclusion}

In recent years, due to the available needs, the subject of doing scientific and field researches to find ways to reduce the projects' failure, and delays and additional costs over their estimated values, project-oriented organizations with complex value chain have adopted some strategies to increase the success rate of projects and to help the project team members in order to improve their performance. In this category, firstly, the capabilities of the project-oriented parent organizations with a suitable approach should be identified and then grouped into a coherent system that forms the organizational capability dimensions and then formulated as an optimized style based on the findings and achievements. Designing and determining the stages of doing research based on the method of case study a based on data qualitative content analysis is suggested. The reason for using this approach is detailed in the text of the article. The main question raised in semi-structured interviews with selected and qualified people is that: "In addition to the pathology of the present situation, what actions are taken by parent organization in regard to increase value-generating in the project management?". Data analysis will be carried out in the same way and with orientation towards answering the research question and using the qualitative analysis method. In order to assess the validity of the obtained results, structure validity and reliability criteria will be used. While, this paper is the first scientific document of the Ph.D. thesis of the research team of the authors of this article, addresses and invites other researchers and enthusiasts of this field to address the issue in various statistical societies.

Implementation of this method in the statistical society of the plans and projects' portfolio of the engineering and development company, which is a subsidiary of the National Iranian Gas Company is carrying out which will soon be published as the second scientific documentary of this research to be used by researchers and thinkers of this field. 


\section{References}

Aali, Samad., Bafandeh Zand, Alireza., Barghi, Amir. 2011. New approach in holding company's strategy: Separation against ownership, Fifth International Conference on Strategic Management.

Abdeh Tabrizi, Hassan., Saleh Ardestani, Abbas. 2013. Organizational Requirements in form of holding for the corporation's financial system in Iran, M.Sc. thesis, University of Tehran.

Adel Mehraban, Marzieh, Iranian Friendship, Mehri. 2015. A Review on Qualitative Content Analysis and its applications in research. Medical Sciences and Health Services University of Isfahan.

Arbabi, Hanei, Sobhie, Mohammad Hussein., Abbaspour, Pegah. 2016. Review of the valuable functions of mother organization in oil industry projects, Faculty of Arts and Architecture, University of Tehran.

Asgari, Mohammad Reza., Soleimani, Azam., Rashidi Aghdam, Mahmoud. 2011. Determining the factors affecting the completion of capital asset procurement projects at the generalized executive parent organizations of buildings and public facilities, University of Allameh Tabatabaie.

Azar, Adel, Razini., Roohollah., Rafati, Mohammad Amin., 2013. Assessment of adaptability of organizational performance measurement models in project-based organizations. M.Sc. thesis, Faculty of Management and Islamic Education.

Balassa, W. and O.I. Tukel, a new framework for determining critical success/failure factors in projects. International Journal of Project Management. )1996(. 14(3): p. 141-151.

Barney, J., Firm resources and sustained competitive advantage. Journal of Management. )1991(. 17(1): p. 99-120.

Brown, C., A comprehensive organizational model for the effective management of project management. South African Journal of Business Management. (2008). 39(3): p. 1-10.

Chandler, A.D., Scale and Scope: The Dynamics of Industrial Capitalism: Harvard University Press) 1990.(

Chen, Z, Lan, Y, Zhao, R, Impacts of risk attitude and outside option on compensation contracts under different information structures, Fuzzy Optimization and Decision Making. (2018). p.13-47.

Cooke-Davies, T., The "real" success factors on projects. International Journal of Project Management. (2002). 20(3): p. 185-190.

Creswell, J.W., (2003). Research design: Qualitative, quantitative, and mixed methods approaches: Sage Publications, Inc.

Davies, A. and T. Brady, Organizational capabilities and learning in complex product systems: towards repeatable solutions. Research policy. (2000). 29(7-8): p. 931-953.

DeFillippi, R.J. and M.B. Arthur, Paradox in Project-Based Enterprise. CALIFORNIA MANAGEMENT REVIEW. (1998). 10(2). p. 125.

Eisenhardt, K.M. and J.A. Martin, Dynamic capabilities: what are they? Strategic Management Journal. (2000). 21(10-11): p. 1105-1121.

Fasihizadeh, Alireza., Zolfaghari, Pegah, Gholizadeh, Ahad. 2013. Determining the legal nature of specialized mother companies and their relationship with affiliated companies and government, Faculty of Economics, University of Tehran. 
Gholizadeh, Mohammad Hassan., Ramezanpour, Ismail, Mobasheri, Agh Mohammad. 2013. Investigating the effectiveness of internal audit in improving the internal control and performance of specialized mother's companies and the subsidiary companies of Mostazafan Foundation of Islamic Revolutionary of Iran, M.Sc. thesis, Faculty of Literature and Human Sciences, University of Tehran.

Hafez Nia, Mohammad Reza. 2009. Introduction to research method in humanities, Sixth Edition, Tehran, Samt Publication.

Haj Shir Mohammadi, Ali. 2016. Project management and control, Third Edition, Isfahan Industrial University Jihad Publication.

Hamel, G. and C. Prahalad, competing for the future: Breakthrough strategies for seizing control of your industry and creating the markets of tomorrow1994: Harvard business school press.

Hanafizadeh, Payam., Salehi Sedghiani, Jamshid., Rajabpour, Ibrahim. 2011. Evaluating electronic readiness in subsidiary companies of parent companies, M.Sc. thesis, Faculty of Management and Accounting, University of Tehran.

Hanafizadeh, Payam., Zarei, Mirza.1394. Valuation of the parent organization's valuegenerated decisions in subsidiary companies, M.Sc. thesis, Faculty of Engineering, University of Tehran.

Hobday, M., The project-based organisation: an ideal form for managing complex products and systems? Research policy. (2000), 29(7-8): p. 871-893.

Jensen, C., S. Johansson, and M. Löfström, Project relationships-A model for analyzing interactional uncertainty. International Journal of Project Management. (2006), 24(1): p. 412.

Junnonen, J.M., Strategy formation in construction firms. Engineering, Construction and Architectural Management. (1998), 5(2): p. 107-114.

Kerzner, H., Project management: a systems approach to planning, scheduling, and controlling Wiley) 2009.(

Kezsbom, D.S.E., K.A., (2001). The new dynamic project management. New York: John Wiley \& Sons, Inc.

Lincoln, Y.S., (2005). Context, lived experience, and qualitative research. Research in organizations: Foundations and methods of inquiry; p. 221-232.

Lindkvist, L., Governing project-based firms: promoting market-like processes within hierarchies. Journal of Management and Governance. (2004), 8(1): p. 3-25.

Lindkvist, L., Project organization: Exploring its adaptation properties. International Journal of Project Management. (2008). 26(1), p. 13-20.

M O'Connor, M. and L. H Reins borough, Quality projects in the 1990s: a review of past projects and future trends. International Journal of Project Management. (1992), 10(2): p. 107-114.

Mantel, S.J., Meredith, J.R., Scott, M.S. \& Sutton, M.M., (2001). Project Management in Practice, New York: John Wiley and Sons, Inc.

Mazloomi, Nader. 2011. Investigating the relationship between environmental uncertainty and organizational structure of the specialized commercial parent company of the Islamic Republic of Iran, M.Sc. thesis, University of Allameh Tabatabaei. 
Miles, M.B. and A.M. Huberman, (1994). Qualitative data analysis: An expanded sourcebook: SAGE publications, Inc.

Milosevic, D. and P. Patanakul, Standardized project management may increase development projects success. International Journal of Project Management. (2005), 23(3): p. 181-192.

Mirshekari, Abbas, Hassan Tavakoli, Atefeh. 2014. Legal analysis of Holdings Company, Faculty of Literature and Humanities, University of Tehran.

Mohaghar, Ali., Jafarnejad, Ahmad., Golabchi, Mahmoud., Jabarzadeh, Younes. 2013. Identifying the capabilities of a project-oriented mother organization: A case study in manufacturing industry, Industrial Management Journal, No. 11.

Mohammadi, Mostafa Abdi, Mehdi. 2013. Explaining the strategic functions of public relations in holding companies, 10th International Conference on Strategic Management.

Nazari, Ahad., Soltanzadeh, Atefe. 2012. Providing a model for the project portfolio management in project-oriented research institutions, M.Sc. thesis, Higher Education Institution of Mehr Alborz.

Prahalad, C.K. and G. Hamel, The core competence of the corporation. Harvard Business Review, (1990), 68(3): p. 79-91.

Rabbiosi, L., Santangelo, G., Parent company benefits from reverse knowledge transfer: The role of the liability of newness in MNEs, Journal of World Business, Elsevier, (2013), Vol (48), p. 160-170.

Richardson, G.B., The organization of industry. The economic journal. (1972), 82(327): p. 883896.

Sattak, Mostafa., Mirfakhar, Atiyeh Sadat. 2012. Providing a framework for selecting the appropriate method for inter-organizational development, M.Sc. thesis, Faculty of Industrial Engineering, University of Tehran.

Snehota, I. and H. Hakansson, (2012). Developing relationships in business networks. Routledge Londres .

Sobhie, Mohammad Hossein, Saeed, Mohammad., Hashemizadeh, Ali. 2013. Strategies for improving projects' portfolio management in contracting project-based organizations, M.Sc. thesis, Faculty of Civil Engineering, University of Tehran.

Sobhie, Mohammad Hossein., Zargarpour, Hamid., Falsafi, Reza. 2011. Review of project portfolio management in project-based organization, M.Sc. thesis, Faculty of Arts and Architecture, University of Tehran.

Teece, D.J., G. Pisano, and A. Shuen, Dynamic capabilities and strategic management. Strategic Management Journal. (1997), 18(7): p. 509-533.

Thiry, M. and M. Deguire, Recent developments in project-based organisations. International Journal of Project Management. (2007), 25(7): p. 649-658.

Turner, J.R., (2009). The handbook of project-based management: leading strategic change in organizations. McGraw-Hill.

Vadastreanu, A., Bot, A., Farcas, F., (2016). Innovation Capability - the mail factor for wealth creation, IEEE Explore.

Verzuh, E., The fast forward MBA in project management. (2015), p.45-48. 
Woodward, J., S. Dawson, and D. Wedderburn, Industrial organization: Theory and practice. (2016), Oxford University Press London .

Yang, K, Zhao, R, Lan, Y, Impacts of uncertain project duration and asymmetric risk sensitivity information in project management, International Transactions in operational research. (2015), p. 1-26.

Yin, R.K., (2009). Case study research: Design and methods. Sage publications, INC. 